\title{
An Open Trial of Pyridostigmine in Post-poliomyelitis Syndrome
}

\author{
Daria A. Trojan and Neil R. Cashman
}

\begin{abstract}
Background: One of the major symptoms of postpoliomyelitis syndrome (PPS) is disabling generalized fatigue. Subjects with PPS also report muscle fatiguability and display electrophysiologic evidence of anticholinesterase-responsive neuromuscular junction transmission defects, suggesting that anticholinesterase therapy may be useful in the management of disabling fatigue. Methods: We initiated an open trial of the oral anticholinesterase pyridostigmine, up to $180 \mathrm{mg}$ per day, in 27 PPS patients with generalized fatigue and muscle fatiguability. Response to pyridostigmine was assessed with the Hare fatigue scale, the modified Barthel index for activities of daily living, and a modified Klingman mobility index. Results: Two patients could not tolerate the medication. After one month of therapy, 16 patients $(64 \%)$ reported a reduction in fatigue on the Hare fatigue scale; three of 16 showed improvement on the modified Barthel index for activities of daily living, and two of 16 experienced improvement on a modified Klingman mobility index. Pyridostigmine responders were significantly more fatigued than non-responders on the pre-treatment Hare score, but were not significantly different with regard to age, sex, age at acute poliomyelitis, or severity of acute poliomyelitis. Conclusions: Pyridostigmine may be useful in the management of fatigue in selected patients with PPS. Response to pyridostigmine may be predicted by severity of pre-treatment fatigue.
\end{abstract}

RÉSUMÉ: Étude ouverte utilisant la pyridostigmine dans le syndrome post-poliomyélite. Introduction: Un des symptômes majeurs du syndrome post-poliomyélite (SPP) est une fatigue généralisée incapacitante. Les patients atteints du SPP rapportent également de la fatigabilité musculaire et les études électrophysiologiques démontrent des défauts de transmission au niveau des plaques neuromusculaire sensibles à l'anticholinestérase, suggérant que la thérapie anticholinestérase pourrait être utile dans le traitement de la fatigue incapacitante. Méthodes: Nous avons entrepris une étude ouverte utilisant la pyridostigmine, une substance anticholinestérase orale, jusqu'à $180 \mathrm{mg}$ par jour chez 27 patients atteints de SPP qui présentaient une fatigue généralisée et de la fatigabilité musculaire. La réponse à la pyridostigmine était évaluée au moyen de l'échelle de fatigue de Hare, de l'indice modifié de Barthel pour les activités de la vie quotidienne et de l'indice modifié de mobilité de Klingman. Résultats: Deux patients n'ont pas pu tolérer la médication. Après un mois de traitement, 16 patients $(64 \%)$ ont rapporté une diminution de la fatigue selon l'échelle de fatigue de Hare; 3 sur 16 présentaient une amélioration selon l'indice modifié de Barthel pour les activités de la vie quotidienne et 2 sur 16 présentaient une amélioration selon l'indice modifié de mobilité de Klingman. Les répondeurs à la pyridostigmine étaient significativement plus fatigués que les non-répondeurs, selon leur score à l'échelle de Hare avant traitement. Cependant, ils n'étaient pas significativement différents quant à l'âge, au sexe, à l'âge au moment de la poliomyélite aiguë ou à la sévérité de la poliomyélite aiguë. Conclusions: La pyridostigmine peut s'avérer utile dans le traitement de la fatigue chez certains patients avec SPP. La réponse au traitement peut être prédite par la sévérité de la fatigue prétraitement.

Can. J. Neurol. Sci. 1995; 22: 223-227

Postpoliomyelitis syndrome (PPS) is a clinical syndrome consisting of new weakness, fatigue, and pain following decades of functional stability after recovery from paralytic poliomyelitis. ${ }^{1-4}$ Generalized systemic fatigue is a common complaint in patients with postpoliomyelitis syndrome (PPS; ${ }^{1-5}$ ). Muscle fatiguability, defined as increased weakness on exertion improving with rest, can also be observed in PPS, ${ }^{6}$ and is similar to that seen in myasthenia gravis ( $\mathrm{MG} ;{ }^{7}$ ) and amyotrophic lateral sclerosis $\left(\mathrm{ALS} ;{ }^{8}\right.$ ). Neuromuscular junction transmission abnormalities as revealed by decrement on repetitive stimulation and increased jitter on single fiber electromyography (SFEMG) are observed in $\mathrm{MG}^{7}{ }^{7} \mathrm{ALS},{ }^{8-12}$ and in patients with antecedent paralytic poliomyelitis. ${ }^{3,13-18}$ In MG, the neuromuscular transmission defect is postsynaptic. ${ }^{7}$ In ALS and PPS, the defect is thought to

From the Department of Neurology, Montreal Neurological Institute and Hospital, McGill University, Montreal.

RECEIVED DECEMBER 6, 1994. ACCEPTED IN FINAL FORM MARCH 29, 1995

Reprint requests to: Daria A. Trojan, M.D., Montreal Neurological Institute, 3801 University Street, Montreal, Quebec, Canada H3A 2B4 
be presynaptic, secondary to defective terminal axonal conduction and/or impaired release of acetylcholine. ${ }^{6,10,16,17,19}$ The oral anticholinesterase agent pyridostigmine is useful in the treatment of muscle fatiguability in MG and ALS. ${ }^{7,8}$ Neuromuscular junction transmission as measured by repetitive stimulation and jitter on stimulation SFEMG can improve with administration of anticholinesterases in PPS. ${ }^{13,17}$ In addition, clinical response to pyridostigmine has been associated with improvement of neuromuscular junction transmission with the short-acting, intravenous, anticholinesterase edrophonium indicating that fatigue in PPS is due to anticholinesterase-responsive neuromuscular junction transmission defects in a proportion of fatigued post-polio patients. ${ }^{17}$ For these reasons, we initiated an open trial to assess the response of disabling fatigue in patients with PPS to pyridostigmine.

\section{Materials and Methods}

\section{Patients}

A series of 27 patients attending a post-poliomyelitis clinic at the Montreal Neurological Institute and Hospital were selected for the study. All patients provided a history consistent with prior paralytic poliomyelitis followed by prolonged convalescence and partial or complete recovery, and at least 10 years of functional stability. Patients were evaluated with a standardized history and physical examination. ${ }^{3}$ All 27 patients provided a complaint of generalized systemic fatigue and muscle fatiguability, and were unresponsive to treatment with more conservative measures. They provided their informed consent to participate in the study.

\section{Methods}

Data obtained on all patients included age at time of study, sex, age at acute paralytic poliomyelitis, years since acute poliomyelitis, and duration of new symptoms. An estimate of severity of initial acute poliomyelitis was made by use of a modified index as described by Klingman et al. ${ }^{20}$ On this 6point measure, one point was given for involvement of each of four extremities (partial or complete paralysis), one point for involvement of speech and/or swallowing, and one point for respiratory involvement (with or without mechanical ventilation). The Hare fatigue symptom scale (Table 1$),{ }^{21}$ the modified Barthel ADL index, ${ }^{22}$ and a modified Klingman mobility index (Table 2$)^{20}$ were determined for each patient before and at least one month following initiation of treatment. Responders were defined as those who experienced an improvement of at least $20 \%$ on initial fatigue scores. The maintenance dosage of pyridostigmine was $60 \mathrm{mg}$ three times a day. To minimize the incidence of side effects, initial dosage was $30 \mathrm{mg}$ every day, increased by $30 \mathrm{mg}$ every other day until the maximum dosage was attained. One patient experienced significant improvement with a minimum of side effects at $120 \mathrm{mg}$ every day, and for this reason was maintained on a lower dosage.

Statistical comparisons between the two groups of patients, "responders" and "non-responders," were performed using the unpaired t-test for continuous data and Fisher's exact test for proportions. The paired t-test was utilized to compare pre-treatment and post-treatment fatigue scores in individual patients. Statistical significance was accepted at $\mathrm{p}<0.05$.
Table 1: Hare Fatigue Symptom Scale.

0 - none

0.5 - very mild

1.0 - mild

1.5 - mild to moderate

2.0 - moderate

2.5 - moderate to severe

3.0 - severe

3.5 - severe to unbearable

4.0 - unbearable

From Hare et al.: Simplified scale for rating perceived exertion in patients with coronary artery disease. Reproduced with permission. Further reproduction of the table requires authorization from the American Academy of Sports Physicians. Ann Sports Med 1985; 2: 64-68. See reference 21.

Table 2: Mobility Index.

0 - no ambulatory difficulties

1 - mild ambulatory difficulties without need for braces

2 - moderate ambulatory difficulties with need for braces

3 - severe ambulatory difficulties with need for braces, and a wheelchair for longer distances

4 - non-ambulatory, wheelchair bound (manual)

5 - non-ambulatory, wheelchair bound (electric)

6 - bedridden

Modified from Klingman et al.: Functional recovery: A major risk factor for the development of postpoliomyelitis muscular atrophy. Reproduced with permission. Copyright 1988, American Medical Association. Modified from Klingman et al. Arch Neurol 1988; 45: 645-647. See reference 20.

\section{RESULTS}

Twenty-seven patients were entered into an open trial to assess the response of PPS fatigue to pyridostigmine. Two patients were unable to tolerate the medication (see below), and were excluded from further analyses. A significant difference in fatigue scores (Hare fatigue symptom scale, $\mathrm{p}<0.0001$, with a mean difference $\pm \mathrm{SD}$ of $1.12 \pm 1.05$ ) was observed when pretreatment and post-treatment fatigue scores were compared in the entire group of 25 patients that was able to tolerate pyridostigmine (Figure 1). Sixteen patients $(64 \%)$ reported an improvement on the Hare fatigue score of 20 to $88 \%$ (mean improvement $56 \%$ ) (Figure 1). Of these 16 patients, three patients improved in activities of daily living (modified Barthel ADL index), two improved on mobility indices (modified Klingman mobility index), and one patient who had been unable to work due to fatigue returned to work after initiation of treatment. Mean fatigue score before treatment in the responders was $3.1 \pm 0.83$ (mean $\pm S D$ ), and after treatment decreased to a mean score of $1.4 \pm 0.64(p<0.0001)$. Mean fatigue score before treatment in the non-responder group was $2.2 \pm 0.94$. This score did not change with treatment. Duration of treatment in the 16 responders has ranged from 0.1 to 2.8 years, with a mean of 1.2 years. Of the 11 patients who did not experience a reduction in fatigue with pyridostigmine or who were unable to tolerate the medication, two developed increased weakness which resolved on discontinuation of the medication. 


\section{Response of Fatigue to Pyridostigmine}

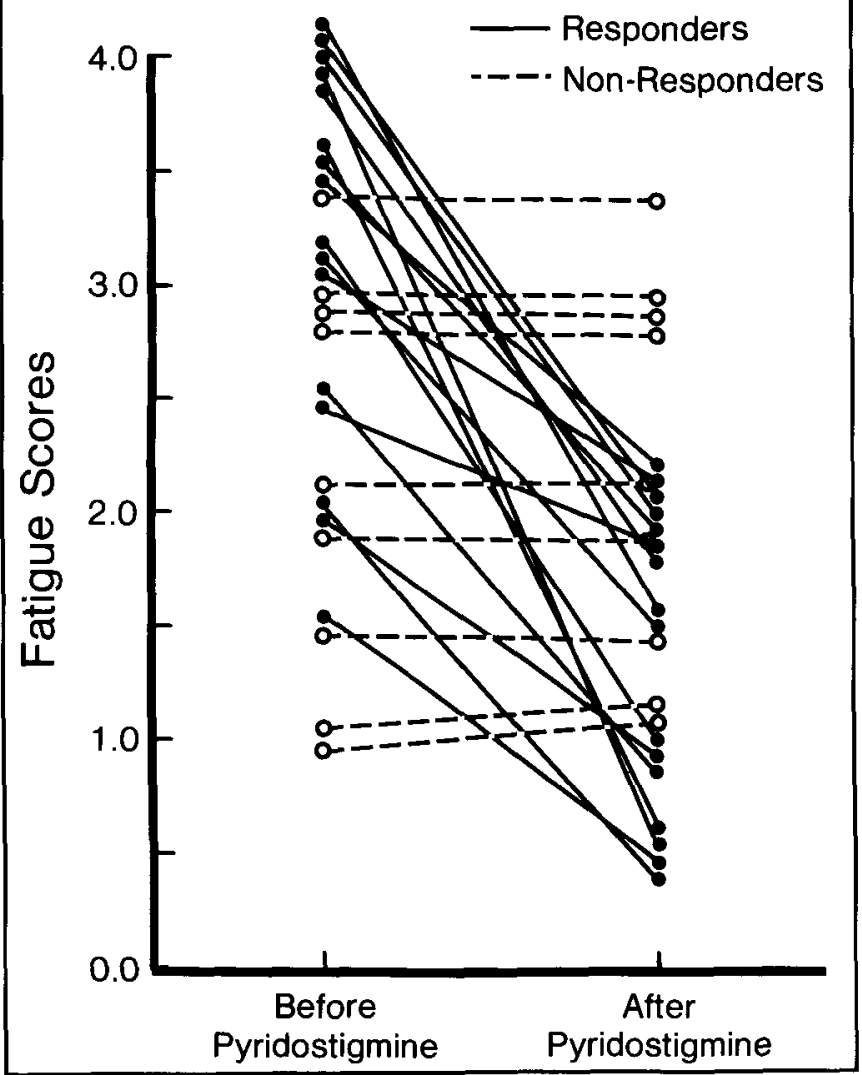

Figure 1: Response of Fatigue to Pyridostigmine. Twenty-seven patients with PPS fatigue were entered into an open trial to assess response of fatigue to pyridostigmine. Two patients were unable to tolerate the medication and are excluded from this figure. Twenty-five patients were treated with pyridostigmine $180 \mathrm{mg} q \mathrm{~d}$ for at least one month. Sixteen patients experienced an improvement of 20 to $88 \%$ (mean 56\%), and 9 patients experienced no improvement in fatigue on Hare fatigue index measured before and at least one month after treatment initiated. Mean fatigue score before treatment in the responders was 3.1, and after treatment decreased to a mean score of 1.4. Mean fatigue score before treatment in the non-responder group was 2.2. This score did not change with treatment.

Some side effects from the medication were noted in $50 \%$ of patients, particularily in the initial stages of treatment. These included diarrhea, gastrointestinal cramps, muscle cramps, blurred vision, and increased urinary frequency. In two patients, persistent symptoms were managed by the addition to pyridostigmine of the muscarinic anticholinergic agents oxybutynin chloride or propantheline bromide, for management of increased urinary frequency and diarrhea.

Historical data in the responders and non-responders was compared in an effort to identify characteristics which could predict response to pyridostigmine. There was no significant difference between the two groups with regard to age, sex, age at time of acute poliomyelitis, severity of acute poliomyelitis, duration of new symptoms, and in initial ADL and mobility scores (Table 3). However, responders were significantly more fatigued than non-responders as determined by pre-treatment Hare fatigue scores $(\mathrm{p}<0.03)$. Two illustrative case reports follow.

\section{Patient 1}

A 44-year-old female with a history of paralytic poliomyelitis at age eight presented to the post-polio clinic with inability to swallow solid food, increased use of a day-time respirator for eight months, increased weakness in all four limbs, and general fatigue. During acute poliomyelitis, she developed paralysis of all four limbs, respiratory involvement requiring use of an iron lung, and involvement of speech and swallowing. She experienced moderate recovery of her weakness, and complete recovery of speech, swallowing, and respiratory function. However, at age 17, new respiratory symptoms necessitated the use of a night-time negative pressure respirator, and at age 40 she started using a day-time positive pressure respirator for five to seven hours per day. Examination revealed kyphoscoliosis, atrophy and weakness in all four limbs, muscle fatiguability, and absent deep tendon reflexes. After failure of nonspecific measures such as discontinuation of lorazepam and activity planning, pyridostigmine $180 \mathrm{mg}$ per day was started. Two weeks following initiation of this medication, the patient was able to reduce use of her day-time respirator from five to seven hours per day, to one to three hours per day. She also experienced reduction of general fatigue (Hare fatigue scale, 4 and 2), and was able to walk at least twice as far as previously, and take much fewer rest periods during the day. Four weeks later she was again able to swallow solid food. Seven months following initiation of pyridostigmine, she was planning to return to part-time work as a school-teacher.

\section{Patient 2}

A 44-year-old woman with a history of poliomyelitis at age 14 presented to the post-polio clinic with complaints of new weakness in her left upper and left lower extremities, general and local muscle fatigue, and pain. At the time of acute poliomyelitis, her left upper extremity was partially paralyzed, and lower extremities were completely paralyzed. She experienced complete recovery of motor strength in her right lower extremity, and significant recovery in left upper and left lower extremities. Over a period of two to three years prior to presentation, she experienced increased left sided weakness, an increased sleep requirement from seven to ten hours per night with an afternoon nap, decreased ability to ambulate, and muscle pain with minimal exertion. She stopped working as a secretary because of her symptoms. Examination revealed no atrophy, mild weakness in the left upper and left lower extremities, and muscle fatiguability. Deep tendon reflexes were brisk, but symmetric in the arms, and normal in the legs. One month later she was started on pyridostigmine $180 \mathrm{mg}$ per day. Her sleeping time decreased to eight hours per day, and the distance she could walk without stopping secondary to muscle pain increased from one block to one mile. Five months following initiation of treatment with pyridostigmine she returned to full time employment.

\section{Discussion}

We have observed in an open trial in 27 patients that disabling general fatigue and muscle fatiguability in a proportion of patients with PPS can be effectively managed with the anticholinesterase agent, pyridostigmine, and that response may be predicted by the severity of pre-treatment fatigue. Sixteen patients experienced improvement in fatigue and functional status. There were no significant differences between responders and non-responders in terms of age, sex, age at acute poliomyelitis, however the two groups of patients were significantly different with regard to reported pre-treatment fatigue scores.

In patients with PPS, conditions causing fatigue, such as other neurological disorders, depression, and a variety of medical diseases must be considered and treated before attributing patient fatigue to PPS. If fatigue is believed to be due to PPS, then conservative measures such as weight loss, energy conservation techniques, better organization of daily activities, and planned short rest periods or naps during the day may be beneficial. If these measures are ineffective or insufficient, treatment with pyridostigmine may be warranted in some patients. Some relative contraindications to pyridostigmine include cardiac 
Table 3: Comparison of Pyridostigmine Responders With Non-Responders.

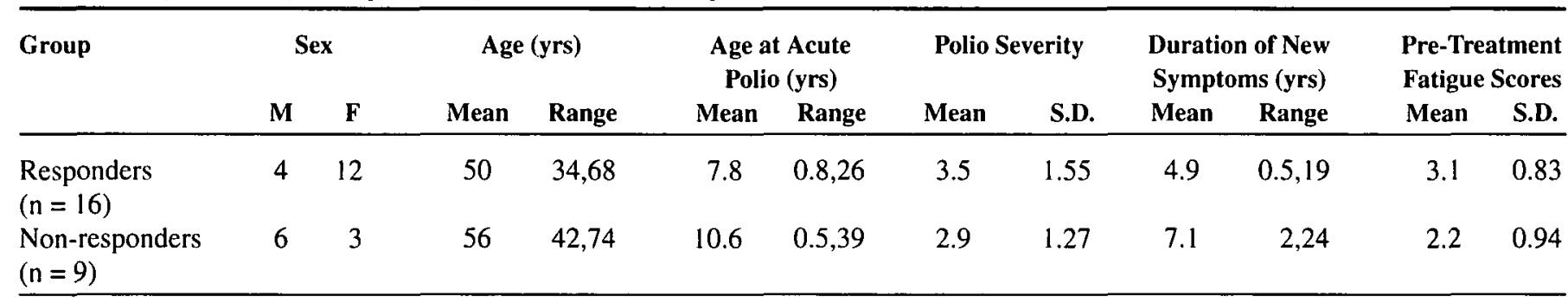

Legend: Responders were significantly more fatigued than non-responders (unpaired t-test, $p<0.05$ ) on pre-treatment Hare fatigue scores. There were no significant differences in age, sex, age at acute polio, severity of acute polio, and duration of new symptoms. $M=m a l e ; F=$ female; yrs = years; S.D. = standard deviation. Severity of acute polio was estimated on a six point scale. Please refer to text for computation of this measure. Pre-treatment fatigue was assessed on a 0 to 4 Hare fatigue symptom scale (see Table 1).

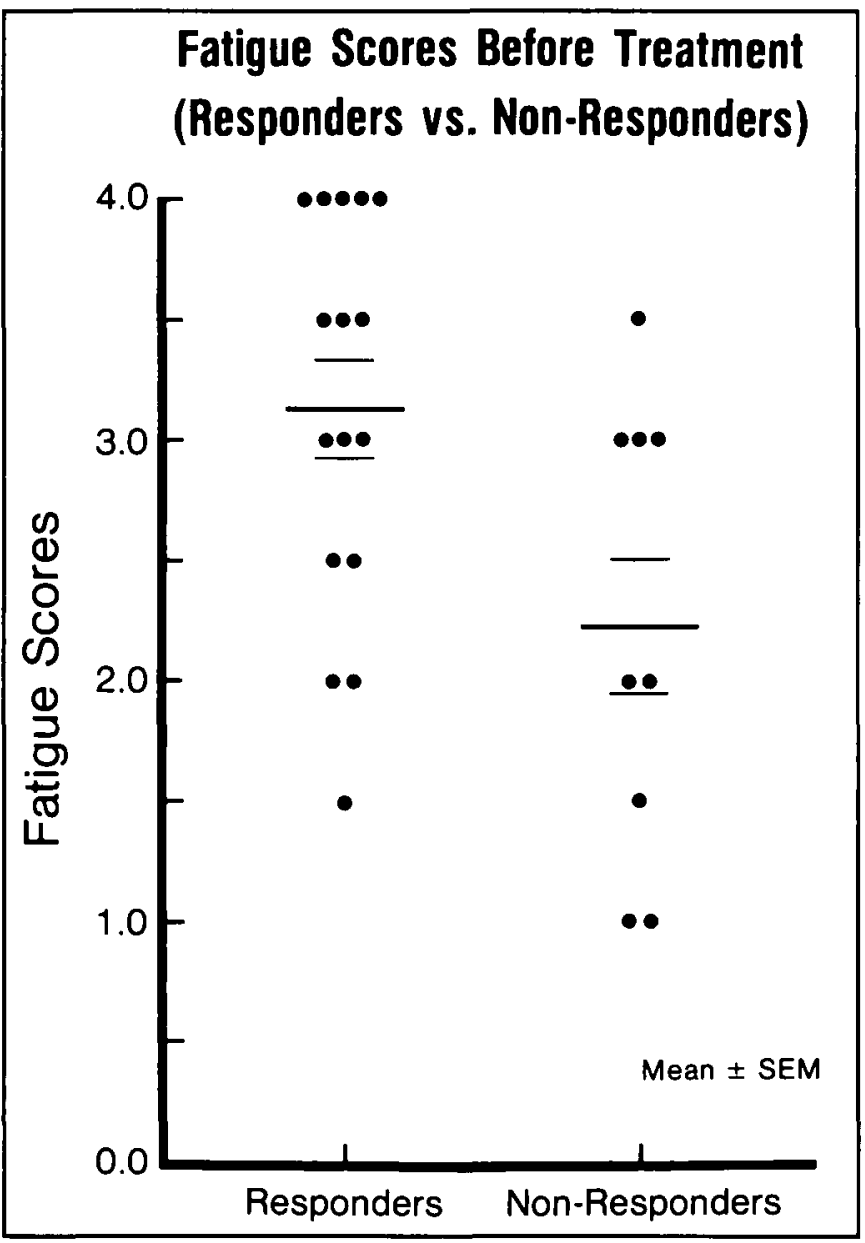

Figure 2: Pre-treatment Fatigue Scores (Responders vs. Non-responders). Twenty-seven PPS patients were entered into an open trial to assess response of PPS fatigue to pyridostigmine. Two patients were unable to tolerate the medication. Twenty-five patients with PPS fatigue were treated with pyridostigmine $180 \mathrm{mg} q$ d for at least one month. Responders $(n=16)$ were significantly more fatigued than non-responders $(n=9)$ on pre-treatment Hare fatigue scores $(p<0.03)$.

arrhythmias, increased bronchial secretions and reactivity, and some urological disorders. Our finding that pyridostigmine was more effective in more severely fatigued patients provides information in determining which patients are more likely to respond to this treatment.
The chronic effects of pyridostigmine in PPS are currently unknown; however anticholinesterase agents have been used effectively in the treatment of $\mathrm{MG}$ for decades. Anticholinesterase agents are associated with acute and chronic toxicities, both pre- and post-synaptically in experimental animals and humans. ${ }^{23-25}$ The doses used in these animal studies and in patients with $\mathrm{MG}$ are manyfold higher than the dose which has been used in this trial in PPS ( 2 g per day in MG versus $180 \mathrm{mg}$ per day in PPS). Pyridostigmine $90 \mathrm{mg}$ per day was recently used in 41,650 soldiers involved in the Gulf War as a pretreatment to possible organophosphate intoxication. A retrospective study found that $50 \%$ of soldiers complained of mild side effects (similar to those noted by us, such as soft stools, urinary frequency, abdominal cramps), $1 \%$ had side effects severe enough to necessitate medical attention, and $<0.1 \%$ discontinued the medication because of side effects. ${ }^{26}$ In addition, pyridostigmine did not affect soldiers' ability to perform. ${ }^{26.27} \mathrm{We}$ also found that side effects occurred commonly, but tended to decrease with chronic administration.

The effect of pyridostigmine on muscular function in PPS has been assessed in seven patients with PPS. ${ }^{28}$ An isokinetic fatigue protocol was performed by these patients while on and off pyridostigmine. Even though total work for the entire group of patients did not differ while on and off the medication, three patients were weaker and one patient demonstrated increased muscle fatiguability while off the medication. Therefore, pyridostigmine may decrease the subjective symptom of fatigue by not only decreasing muscle fatiguability, but also increasing strength. The basis for the latter effect may be due to enhancing neuromuscular transmission at suboptimally functioning synapses.

Fatigue in PPS has been attributed to a number of sources, both central and peripheral. ${ }^{29}$ Possible central causes of fatigue are dysfunction of the reticular activating system, chronic pain including fibromyalgia, depression, sleep disorders, and respiratory dysfunction. $^{30-34}$ Proposed peripheral causes of fatigue include metabolic exhaustion of enlarged post-polio motor units, neuromuscular junction transmission defects, and muscular abnormalities. ${ }^{6.17 .35-37}$ Our data suggest that fatigue in PPS may be multifactorial in nature, but that anticholinesterase-responsive neuromuscular junction transmission defects account for a proportion of this fatigue.

Since our study was an open trial that measured responses of subjective complaints quantitatively, it should be considered preliminary. By employing a specific therapeutic agent, we obtained a response rate of $64 \%$ in a selected group of patients, which is higher than that generally attributed to placebo. ${ }^{38}$ 
Based on these encouraging results, a randomized, placebo-controlled, double-blinded trial of pyridostigmine in PPS should be carried out. Pyridostigmine may prove to be a safe and effective treatment of a major disabling symptom of PPS.

\section{ACKNOWLEDGEMENTS}

This work was supported in part by the Fonds de la recherche en santé du Québec, the Quebec March of Dimes, and the Association Polio Québec. We are indebted to the reviewers for their constructive criticism, and to the patients who participated in the study.

\section{REFERENCES}

1. Codd MB, Mulder DW, Kurland LT, Beard CM, O'Fallon WM. Poliomyelitis in Rochester, Minnesota, 1935-1955: Epidemiology and long-term sequelae. A preliminary report. In: Halstead LS, Wiechers DO, eds. Late Effects of Poliomyelitis. Miami, FL: Symposia Foundation, 1985: 121-134.

2. Halstead LS, Weichers DO, Rossi CD. Late effects of poliomyelitis: a national survey. In: Halstead LS, Wiechers DO, eds. Late Effects of Poliomyelitis. Miami, FL: Symposia Foundation, 1985: 11-31.

3. Cashman NR, Maselli R, Wollman RL, et al. Late denervation in patients with antecedent paralytic poliomyelitis. $N$ Engl $J$ Med 1987; 317:7-12.

4. Halstead LS, Rossi CD. Post-polio syndrome: clinical experience with 132 consecutive outpatients. In: Halstead LS, Wiechers DO, eds, Research and Clinical Aspects of the Late Effects of Poliomyelitis. White Plains, NY: March of Dimes Birth Defects Foundation, 1987: 13-26.

5. Trojan DA, Cashman NR. Treatment of fatigue in the postpoliomyelitis syndrome with pyridostigmine. Arch Phys Med Rehabil 1989: 70: A42 (abstract).

6. Jubelt B, Cashman NR. Neurological manifestations of the postpolio syndrome. Crit Rev Neurobiol 1987; 3: 199-220.

7. Engel AG. Acquired autoimmune myasthenia gravis. In: Engel AG, Banker BQ, eds, Myology. New York, NY: McGraw Hill Inc., 1986: 1925-1954.

8. Mulder DW, Lambert EH, Eaton LM. Myasthenic syndrome in patients with amyotrophic lateral sclerosis. Neurology 1959; 9 : $627-631$.

9. Stalberg E, Ekstedt J, Broman A. Neuromuscular transmission in myasthenia gravis studied with single fiber electromyography. J Neurol Neurosurg Psychiatry 1974; 37: 540-547.

10. Stalberg E, Schwartz MS, Trontelj JV. Single fiber electromyography in various processes affecting the anterior horn cell. J Neurol Sci 1975; 24: 403-415.

11. Denys EH, Norris FH. Amyotrophic lateral sclerosis impairment of neuromuscular transmission. Arch Neurol 1979; 36: 202-225.

12. Bernstein LP, Antel JP. Motor neuron disease: decremental response to repetitive nerve stimulation. Neurology 1981;31: 204-207.

13. Hodes R. Electromyographic study of defects of neuromuscular transmission in human poliomyelitis. Arch Neurol Psychiatr 1948: 60: 457-473

14. Wiechers DO, Hubbell SL. Late changes in the motor unit after acute poliomyelitis. Muscle Nerve 1981; 4: 524-528.

15. Dalakas MC, Elder G, Hallett $M$, et al. A long-term follow-up study of patients with post-poliomyelitis neuromuscular symptoms. N Engl J Med 1986; 314: 959-963.

16. Wiechers DO. New concepts of the reinnervated motor unit revealed by vaccine-associated poliomyelitis. Muscle Nerve 1988; $11: 356-368$

17. Trojan DA, Gendron D, Cashman NR. Anticholinesterase-responsive neuromuscular junction transmission defects in postpoliomyelitis fatigue. J Neurol Sci 1993; 114: 170-177.
18. Trojan DA, Gendron D, Cashman NR. Stimulation frequency-dependent neuromuscular junction transmission defects in patients with prior poliomyelitis. J Neurol Sci 1993; 118: 150-157.

19. Bradley WG. Recent views on amyotrophic lateral sclerosis with emphasis on electrophysiological studies. Muscle Nerve 1987; 10: 490-502.

20. Klingman J, Chui H, Corgiat M, Perry J. Functional recovery: a major risk factor for the development of postpoliomyelitis muscular atrophy. Arch Neurol 1988: 45: 645-647.

21. Hare TW, Hakki AH, Lowenthal DT, Iskandrian AS, Segal BL. Simplified scale for rating perceived exertion in patients with coronary artery disease. Ann Sports Med 1985; 2: 64-68.

22. Granger CV. Health accounting: functional assessment of the longterm patient. In: Kottke FJ, Stillwell GK, Lehmann JF, eds. Krusssen's Handbook of Physical Medicine and Rehabilitation. Philadelphia, PA: W.B. Saunders, 1982: 253-274.

23. Munsat TL. Anticholinesterase abuse in myasthenia gravis. J Neurol Sci 1984; 64: 5-10

24. Engel AG, Lambert EH, Santa T. Study of long-term anticholinesterase therapy: effects on neuromuscular transmission and on motor end-plate fine structure. Neurology 1973; 23: 1273-1281.

25. Hudson CS, Rash JE, Tiedt TN, Albuquerque EX. Neostigmineinduced alterations at the mammalian neuromuscular junction. II. Ultrastructure. J Pharm Exp Ther 1978; 205: 340-356.

26. Keeler JR, Hurst CG, Dunn MA. Pyridostigmine used as a nerve agent pretreatment under wartime conditions. JAMA 1991: 266: 693-695.

27. Cook JE, Wenge B, Kolka MA. Chronic pyridostigmine bromide administration: side effects among soldiers working in a desert environment. Military Med 1992; 157: 250-254.

28. Kilfoil M, St Pierre DM, Trojan DA, Cashman NR. The effects of pyridostigmine (Mestinon) on isokinetic evaluation of fatigue in subjects with post-poliomyelitis syndrome. Phys Ther 1992; 72: S112 (abstract).

29. Gow PJ, Stokes M, Edwards RHT, Investigations of neuromuscular performance in post-polio patients: a practical approach. In: Halstead LS, Wiechers DO, eds. Research and Clinical Aspects of the Late Effects of Poliomyelitis, White Plains, NY: March of Dimes Birth Defects Foundation, 1987: 293-300.

30. Kohl SJ. Emotional responses to the late effects of poliomyelitis. In: Halstead LS, Wiechers DO, eds. Research and Clinical Aspects of the Late Effects of Poliomyelitis. White Plains, NY: March of Dimes Birth Defects Foundation, 1987: 135-143.

31. Fischer DA. Sleep-disordered breathing as a late effect of poliomyelitis. In: Halstead LS, Wiechers DO, eds. Research and Clinical Aspects of the Late Effects of Poliomyelitis. White Plains, NY: March of Dimes Birth Defects Foundation, 1987: 115-120.

32. Halstead LS. Post-polio syndrome: definition of an elusive concept. In: Munsat TL, ed. Post-Polio Syndrome. Boston. MA: Butterworth-Heinemann, 1991: 23-28.

33. Bruno RL, Frick NM, Cohen J. Polioencephalitis, stress, and the etiology of post-polio sequelae. Orthopedics 1991; 14: 1269-1276.

34. Trojan DA, Cashman NR. Fibromyalgia is common in a postpoliomyelitis clinic. Arch Neurol 1995 (in press).

35. Munsat TL, Andres $P$, Thibideau L. Preliminary observations on long-term muscle force changes in the post-polio syndrome. $l \mathrm{~m}$ : Halstead LS, Wiechers DO, eds. Research and Clinical Aspects of the Late Effects of Poliomyelitis. White Plians, NY: March of Dimes Birth Defects Foundation, 1987: 329-334.

36. Perry J, Barnes G, Gronley JK. The post-polio syndrome: an overuse phenomenon. Clin Orth Rel Res 1988; 233: 145-162.

37. Sharma KR, Kent-Braun J, Mynhier MA, Weiner MW, Miller RG. Excessive muscular fatigue in the postpoliomyelitis syndrome. Neurology 1994; 44: 642-646.

38. Fletcher RH, Fletcher SW, Wagner EH. Clinical epidemiology: the essentials. Baltimore, MD: Williams and Wilkins, 1988: 140 